\title{
Dysfunctional HDL and Cardiovascular Disease Risk in Individuals with Diabetic Dyslipidemia
}

Omeed Elboudwarej*, Houmehr Hojjat, Shila Safarpoor, Samra Vazirian and Sheila Ahmadi

Department of Medicine, David Geffen School of Medicine at UCLA, Los Angeles, CA 90095-1679, USA

\section{Key Points}

Diabetic dyslipidemia is associated with increased risk of cardiovascular disease.

Diabetic dyslipidemia is characterized by increased plasma triglyceride concentration, increased concentration of small dense LDL cholesterol, and low HDL cholesterol concentration.

HDL normally plays a cardioprotective role by promoting reverse cholesterol transport and modulating inflammation.

- Although HDL is anti-inflammatory in the absence of prolonged oxidative stress, it can become dysfunctional and atherogenic in the chronic inflammatory state that characterizes diabetes mellitus.

Despite therapeutic lifestyle changes and optimal statin therapy, there still remains significant residual cardiovascular risk.

Novel therapies that improve the antioxidant and anti-inflammatory properties of HDL may be the most effective adjunctive treatments for reducing cardiovascular risk in diabetic individuals.

\section{Introduction}

Cardiovascular disease (CVD) remains the leading cause of morbidity and mortality in individuals with diabetes mellitus despite advances in the prevention and management of CVD. A number of studies have shown that the prospective risk of adverse cardiovascular events in diabetic individuals without previous myocardial infarctionis comparable to non-diabetic individuals with myocardial infarction, with comparatively worse clinical outcomes for diabetic individuals following an adverse cardiovascular event [1-4]. Furthermore, population studies indicate that diabetes amplifies the effects of other common CVD risk factors, including hypertension, hypercholesterolemia, and smoking [5,6]. Consequently, diabetes has been considered in some prevention guidelines as a coronary artery disease-risk equivalent $[7,8]$.

Diabetic individuals have a 2- to 4 -fold greater risk of developing CVD in part because of an accelerated atherosclerotic process resulting from the disruption of the regulatory role insulin plays in lipoprotein and plasma lipid metabolism [9]. Dyslipidemia is more frequent in diabetics than age- and sex-matched non-diabetic individuals and can match any of the lipid profiles seen in the general population; however, diabetic dyslipidemia is most often characterized by high plasma triglyceride concentration, low high-density lipoproteincholesterol (HDL-C) concentration, and increased concentration of small dense low-density lipoprotein cholesterol (LDL-C) [10-14].

\section{Pathophysiology of diabetic dyslipidemia}

The diabetic lipid profile is a result of elevated free fatty acid release from insulin-resistant fat cells [15-18]. The excess free fatty acids are then converted to triglycerides in the liver, whose increased production in turn stimulates VLDL cholesterol (VLDL-C) and apolipoprotein B synthesis; the reduced activity of lipoprotein lipase in the insulindeficient state may also contribute to elevated triglyceride and VLDL-C levels $[19,20]$. The consequence of these elevated lipid fractions is increased small dense LDL-C levels and decreased HDL-C (Figure 1).

Specifically, there is an exchange between the HDL-transported cholesterol ester and the VLDL-transported triglyceride mediated by cholesteryl ester transfer protein (CETP). This exchange results in triglyceride-rich HDL particles that are subsequently hydrolyzed by hepatic lipase or lipoprotein lipase. The apolipoprotein A-I (apoA-I)

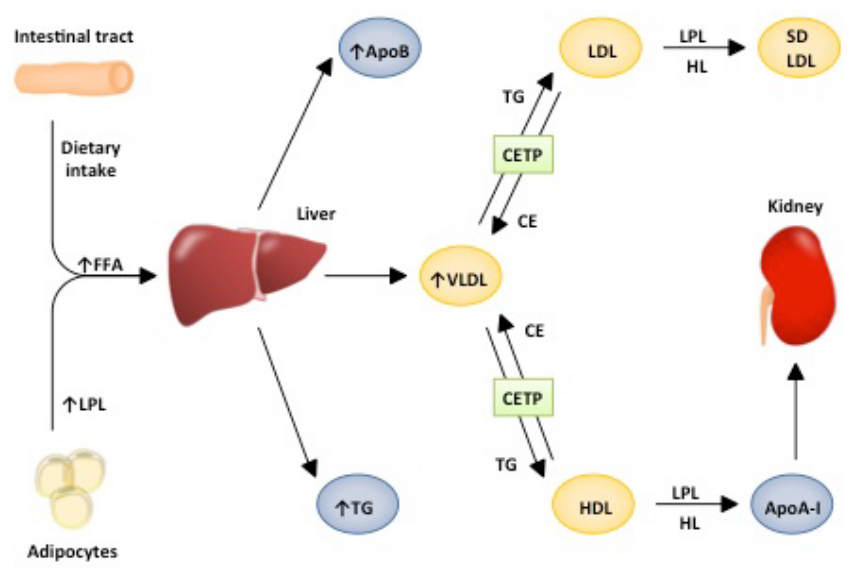

Figure 1: Pathophysiology of diabetic dyslipidemia. Insulin resistance leads to the characteristic triad of high small dense low-density lipoprotein (LDL) level, high triglyceride level, and low high-density lipoprotein (HDL) cholesterol level. In a normal physiologic state, insulin suppresses lipolysis from adipose tissue and hepatic production of very low-density lipoprotein (VLDL) and apolipoprotein B (apoB). However, insulin resistance and hyperinsulinemia in the post-prandial state results in an increased level of VLDL-transported triglyceride, which promotes the transfer of HDL cholesteryl ester and LDL cholesterylester via cholesteryl ester transfer protein (CETP). The triglyceriderich HDL or LDL then undergo hydrolysis by lipoprotein lipase or hepatic lipase, resulting in the production of smaller, denser particles. In addition, the smaller HDL particles are more readily catabolized, resulting in low HDL levels. Abbreviations: ApoA-I, apolipoprotein A-I; ApoB, apolipoprotein B; CE, cholesteryl ester; CETP, cholesteryl ester transfer protein;FFA free fatty acid; $\mathrm{HL}$, hepatic lipase;LPL, lipoprotein lipase; SD LDL, small dense LDL; TG, triglyceride.

*Corresponding author: Omeed Elboudwarej, Department of Medicine, David Geffen School of Medicine at UCLA, Los Angeles, CA 90095-1679, USA, Tel: 9253300837; E-mail: oelboudwarej@mednet.ucla.edu

Received September 22, 2011; Accepted November 20, 2011; Published November 25, 2011

Citation: Elboudwarej O, Hojjat H, Safarpoor S, Vazirian S, Ahmadi S (2011) Dysfunctional HDL and Cardiovascular Disease Risk in Individuals with Diabetic Dyslipidemia. J Diabetes Metab S4:001. doi:10.4172/2155-6156.S4-001

Copyright: @ 2011 Elboudwarej O, et al. This is an open-access article distributed under the terms of the Creative Commons Attribution License, which permits unrestricted use, distribution, and reproduction in any medium, provided the original author and source are credited. 
released from this enzymatic hydrolysis is then filtered through the renal glomeruli and broken down [20,21]. Similarly, CETP is responsible for the exchange of LDL-transported cholesteryl ester and the VLDL-transported triglyceride, with the resulting triglyceride-rich LDL undergoing hydrolysis by hepatic lipase or lipoprotein lipase to become lipid-depleted small dense LDL particles. These small dense LDL particles are more atherogenic and more susceptible to oxidation when glycated [22].

Insulin resistance also contributes to functional changes in the enzymes involved in HDL-C metabolism [23,24]. Cholesterol esterification within the lipoprotein particles via lecithin-cholesterol acyltransferase (LCAT) is only mildly increased relative to the increase in CETP activity; this discrepancy in enzymatic activity levels leads to lower HDL-C levels because of the greater efflux of cholesterol ester from HDL $[20,25]$. The decreased ratio of lipoprotein lipase to hepatic lipase is another contributing factor to lower HDL-C in diabetic individuals [20]. In kinetic studies, individuals with metabolic syndrome had significantly lower adiponectin levels than normal subjects, which strongly correlates with increased fractional clearance rate of apoA-I and, consequently, lower HDL-C [26]. Phospholipidtransfer protein, an enzyme involved in lipoprotein metabolism, has increased activity in diabetes mellitus and is a positive determinant of intima-media thickness in type 2 diabetes mellitus, indicating it may be involved in accelerated atherosclerosis [27].

\section{The cardiovascular role of $\mathrm{HDL}$}

It is well accepted that HDL-C levels are inversely correlated with the risk of adverse cardiovascular events. HDL particles are highly heterogeneous molecules that act as a shuttle to promote reverse cholesterol transport from lipid-laden arteries to the liver for excretion. The major component of HDL responsible for this cholesterol efflux is apoA-I [28]. Moore et al. (2005) showed that knockout mice lacking apoA-I had increased atherosclerosis and impaired reverse cholesterol transport as well as increased systemic inflammation [29].

In addition to its role in cholesterol homeostasis, HDL particles contain varying levels of antioxidants and pro-oxidants that modulate systemic inflammation; these functions appear to have evolved as part of the innate immune system. Several of the antioxidant enzymes associated with HDL includeLCAT, paraoxonase-1 (PON1), platelet-activating factor acetylhydrolase (PAF-AH), and glutathione peroxidase [30]. These enzymes can prevent the formation of oxidized phospholipids or inhibit their activity after they have formed.

Cell culture studies wherein human aortic endothelial cells and smooth muscle have been used to simulate the arterial wall show that adding LDL results in subendothelial deposition [31]. This deposition results in the release of pro-inflammatory cytokines from arterial cells, such as monocyte chemoattractant protein-1 (MCP-1), and oxidation of LDL phospholipids [31]. The addition of normal HDL abolishes this process, indicating that normal HDL is capable of preventing LDL oxidation as well as the LDL-induced inflammatory response [31]. HDL has also been shown to oppose several of the processes associated with endothelial dysfunction by reducing cytokine-induced adhesion molecule expression, increasing nitric oxide production, and inhibiting endothelial apoptosis by HDL-associated lysosphingolipids [32-34]. In vitro studies show that HDL inhibits agonist-stimulated decreases in platelet reactivity and aggregability, fibrinogen binding, and liberation of thromboxane $\mathrm{A}_{2}$ [35].

\section{Inflammatory properties of HDL in chronic disease states}

However, there is emerging evidence that HDL-C levels do not always accurately predicted the function of HDL. Even in the original Framingham study that established the importance of HDL-C levels in predicting adverse cardiovascular events, more than $40 \%$ of events occurred in subjects with clinically normal HDL-C levels [36-38]. This discrepancy is partially attributable to the fact that the function of HDL is adversely affected in pro-inflammatory states.

Van Lenten et al. (1995) were the first to document that during the acute-phase response in rabbits, mice, and humans, HDL loses its ability to inhibit LDL oxidation [39]. Comparison of HDL isolated before, during, and after elective surgery in the same subjects showed that the HDL during surgery was less effective in inhibiting LDL oxidation and actually increased LDL-induced MCP-1 production [39]. In addition, two of the HDL-associated antioxidant enzymes, PON1 and PAF-AH, had reduced activity. Upon resolution of the acute-phase response, these HDL-associated enzyme activities returned to baseline and the anti-inflammatory properties of HDL were restored.

Specifically, the enzymes of the HDL particle responsible for reducing oxidized phospholipids can also be inactivated by these same oxidized phospholipids and reactive oxygen species; in healthy individuals, there is a balance created such that there are enough functioning enzymes and apoA-I activity for HDL to remain antiinflammatory [40,41]. However, in those with chronic illnesses characterized by systemic oxidative stress, such as diabetes, the balance can shift. HDL not only becomes dysfunctional because its inactivated enzymes and altered apolipoproteins cannot adequately promote cholesterol efflux, but actually transforms to a pro-inflammatory molecule as it continues to accumulate oxidized lipids and proteins [42]. Thus, the pro-inflammatory HDL becomes a form of "chronic acute-phase response," similar to that characterized by C-reactive protein levels.

\section{Function of HDL in diabetes mellitus}

Under hyperglycemic conditions, HDL undergoes glycation and has a reduced capacity for metabolizing membrane lipid hydroperoxides, which can lead to increased susceptibility to CVD (Figure 2) [43]. Glycation of HDL by incubation under hyperglycemic conditions results in increased monocyte adhesion to human aortic endothelial cells exposed to oxidized LDL [43]. Furthermore, glycation of the HDL-associated enzyme PON1 inhibits its ability to decrease monocyte-chemotactic protein-1 (MCP-1) production by endothelial cells, thereby preventing monocyte adhesion to endothelial cells in one of the earliest processes of atherosclerosis [44]. Hedrick et al. (2000) found that in subjects with type 2 diabetes mellitus and documented coronary artery disease, PON1 activity was reduced by $40 \%$ compared with non-diabetic subjects [43]. Other studies show an inverse relationship between PON1 activity and circulating oxidized LDL levels in diabetic individuals, highlighting the critical role of PON1 in retarding LDL oxidation $[45,46]$.

Morgantini et al. (2011) compared the anti-inflammatory function in HDL from diabetic subjects compared to healthy volunteers using cell-free assays [47]. HDL from diabetic subjects has higher intrinsic oxidation and was less able to inhibit the migration of monocytes induced by LDL. The mean HDL inflammatory index value in diabetics was significantly greater than $1.0(1.42 \pm 0.29)$, indicating the HDL was actually pro-inflammatory; the HDL inflammatory index has been significantly correlated with intima media thickening and 

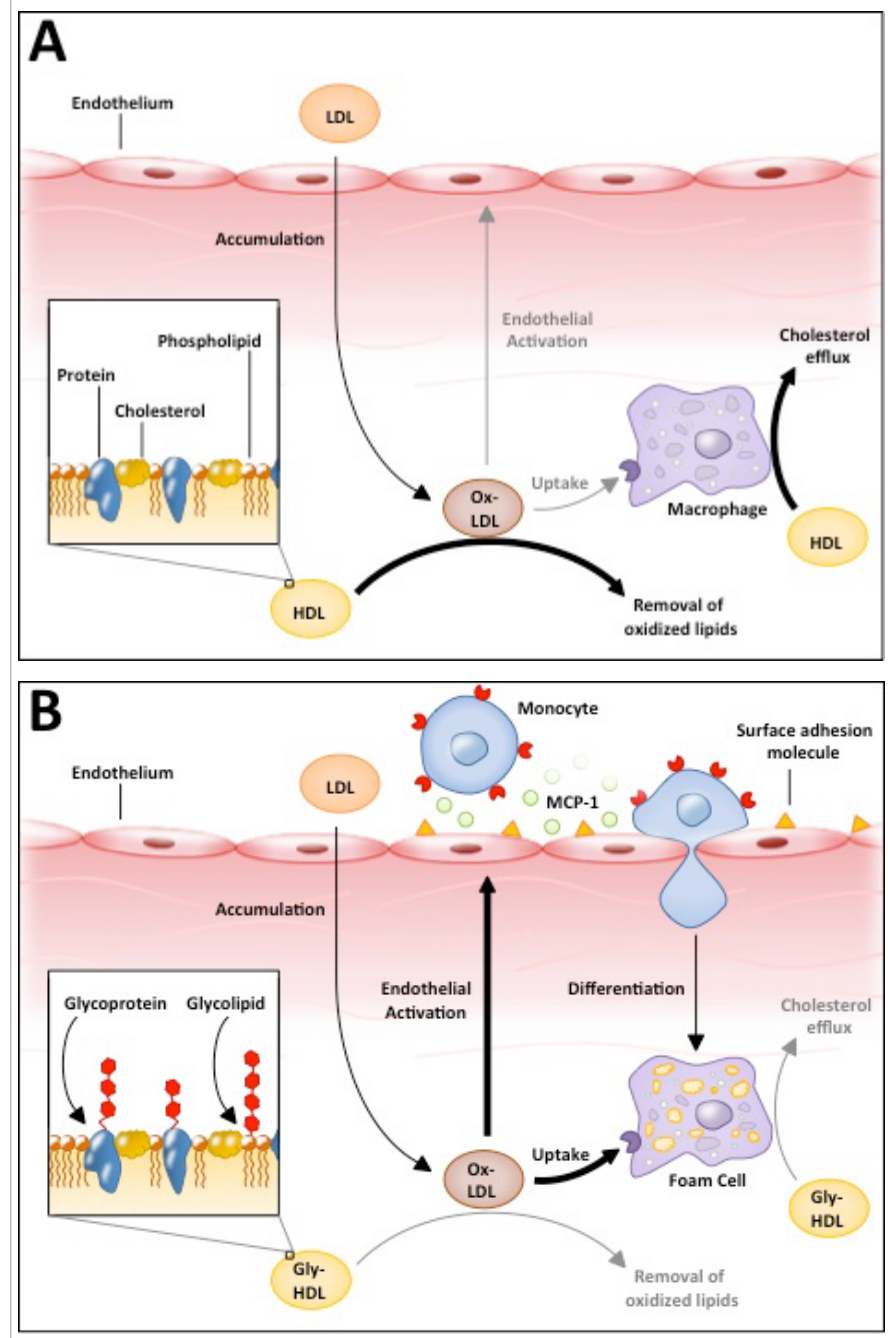

Figure 2: Function of HDL in normal versus hyperglycemic state. (A) In early atherogenesis, hypercholesterolemia promotes accumulation of LDL particles in the arterial subendothelial space. LDL accumulation provokes an inflammatory response that results in oxidative modification of LDL and, subsequently, an augmented expression of various leukocyte adhesion molecules expressed on the surface of the arterial endothelial cells. Healthy $\mathrm{HDL}$ functions to sequester oxidized lipid products from LDL and promote reverse cholesterol transport from macrophages whose scavenger receptors preferentially bind modified lipoproteins, thereby preventing atheroma formation. (B) Under hyperglycemic conditions, the ability of HDL to metabolize and remove oxidized lipids is compromised by glycation. The enhanced lipid peroxidation causes the endothelium to produce monocyte chemoattractants and express leukocyte adhesion molecules. Continued macrophage uptake of oxidized LDL phospholipids and diminished HDL-mediated cholesterol efflux results in atheroma formation. The oxidation of HDL-associated antioxidants via glucose-mediated oxidative stress eventually results in HDL particles that act as pro-inflammatory molecules, further exacerbating the local inflammatory cycle. Abbreviations: Gly-HDL, glycosylated high-density lipoprotein; HDL, high-density lipoprotein; LDL, low-density lipoprotein; MCP-1, monocyte chemotactic protein 1; Ox-LDL, oxidized low-density lipoprotein.

atherosclerotic plaque size [48].Moreover, there was a statistically significant correlation found between HDL inflammatory index values and serum amyloid A (SAA). The presence of acute phase proteins, such as SAA and the haptoglobin-hemoglobin complex, may be implicated in promoting qualitative changes in HDL $[49,50]$.

In healthy individuals, HDL is effective in reversing the inhibition of vasodilatation induced by oxidized LDL. Perségol et al. (2006) found that HDL taken from subjects with type 1 and type 2 diabetes mellitus was defective in counteracting the effects of oxidized LDL on vascular relaxation compared to normal subjects [51,52]. These results suggest that while the etiologies of type 1 and type 2 diabetes mellitus are different, the abnormalities in the function of HDL that result from these disease states are similar.

\section{HDL-C as a predictor of cardiovascular risk}

The current practice in lipid management is that raising HDL-C will necessarily reduce the likelihood of adverse cardiovascular events in diabetics. This treatment goal is supported by strong epidemiologic data confirming the relationship between low HDL-C levels and increased risk for CVD [53,54]. However, measuring HDL-C levels only provides a quantitative measurement of HDL without conveying any information about the qualitative function of the particles themselves. Roberts et al. (2006) found that a 3-week residential program of diet and daily aerobic exercise in obese men with characteristics of metabolic syndrome resulted in improved anti-inflammatory properties of HDL despite an overall reduction of HDL-C levels [55]. A meta-regression analysis by Briel et al. (2009) showed that, after adjustment for changes in LDL-C, no correlation was observed between HDL-C elevation and risk for adverse cardiovascular events or mortality [56]. In another study looking at individuals with a mutant apoA-I protein (apoA- $\mathrm{I}_{\text {Milano }}$ ) that causes reduced HDL-C levels, the subjects did not appear to have an increased risk for adverse cardiovascular events [57]. Analysis of the IDEAL (Incremental Decrease in Endpoints through Aggressive Lipid lowering) and EPIC-Norfolk (European Prospective Investigation Into Cancer in Norfolk) data showed that very high HDL-C levels and particle size were associated with greater cardiovascular risk after adjusting for other cardiac risk factors [58]. These findings indicate that improving HDL composition and function may be as important as assessing HDL-C levels in determining cardiovascular risk.

\section{HDL as a potential therapeutic target}

Treatment strategies have focused on three areas for improving diabetic dyslipidemia: 1) therapeutic lifestyle changes (TLC) with diet, exercise, and weight loss; 2) glycemic control; and 3) lipid profile modification. TLC alone has not been shown to effectively reduce CVD morbidity and mortality, but is an important adjunct to drug-based therapies [59]. Glycemic control helps improve the lipid profile, but is only partially corrective because of continued insulin resistance [60,61]. In particular, glycemic control is more effective in lowering non-HDL-C and triglycerides than increasing HDL-C [62,63].

As in all individuals with dyslipidemia, lipid profile modification in individuals with diabetes has primarily targeted lowering LDL-C given the unequivocal improvement in cardiovascular risk while on statin therapy [64]. Despite this improvement, there still remains considerable residual cardiovascular risk and continued disease progression in the coronary arteries even after optimal statin therapy [65-67]. There is greater interest among researchers in developing novel therapies that target HDL-C as a complement to LDL-C lowering for cardiovascular risk reduction.

The addition of functional, non-oxidized HDL has been shown to be beneficial in diabetic individuals. Drew et al. (2009) showed that infusion of reconstituted HDL particles in type 2 diabetic subjects decreased plasma glucose levelsby increasingboth plasma insulin levels and AMP-activated protein kinase in skeletal muscle [68]. Infusion of reconstituted HDL in diabetic individualsalso enhanced cholesterol efflux by $325 \%$ and reduced the cholesterolcontent of platelet 
membranes, thereby inhibiting the heightened reactivity of platelets normally found in a hyperglycemic state [69]. Additional studies have shown that functional HDL in a model of diabetes helps mitigate the progression of beta cell failure, improves metabolic control, reduces monocyte adhesion, enhances endothelial cell function, and increases levels of circulating endothelial progenitor cells [70-73].

A number of new investigational therapies are being tested that use various physiologic pathways to promote either HDL functionality or raise HDL-C levels, or both (Figure 3).

\section{Drug therapies that primarily improve the quality of HDL}

The drug class that has specifically been shown to improve the function of HDL is the apolipoprotein mimetic peptides, which are short 18-amino acidpeptides that do not have sequence homology with apoA-I, but mimic the class A amphipathic helixes contained in apoA-I [74-76]. ApoA-I, which is the major protein in HDL, plays a number of important biological functions and has anti-atherogenic, antiinflammatory, and antioxidant properties [77]. Similar to endogenous apoA-I, it is postulated that apolipoprotein mimetic peptides appears bind and remove oxidized lipids to help render HDL anti-inflammatory while also promotingcholesterol efflux, without a significant change in HDL-C levels [78,79].

Kruger et al. (2005) studied the concentrations of the antioxidant enzymes heme oxygenase 1 (HO-1) and extracellular superoxide dismutase (EC-SOD) in streptozotocin-induced diabetic rats [80]. The induction of diabetes was associated with a significant decrease in aortic HO-1 and EC-SOD levels without a fall in $\mathrm{Cu} / \mathrm{Zn}$ superoxide dismutase levels. However, treatment of the rats with the apoA-I mimetic peptide $\mathrm{D}-4 \mathrm{~F}$ resulted in a significant increase in aortic $\mathrm{HO}-1$ concentration and activity as well as preservation of EC-SOD levels compared to control non-diabetic rats. Furthermore, D-4F addition helped reduce endothelial sloughing and preserved endothelial nitric oxide synthase (eNOS) mediated vascular reactivity.

Peterson et al. (2007) looked at the effect of D-4F on rats with and without diabetes [81]. Insulin was administered to the streptozotocininduced diabetic rats to maintain blood glucose levels between 240 and $320 \mathrm{mg} / \mathrm{dL}$ to prevent ketosis and weight loss. Four groups of animals were studied: control, streptozotocin-insulin treated, streptozotocin-insulin treated plus $\mathrm{D}-4 \mathrm{~F}$, and rats treated with $\mathrm{D}-4 \mathrm{~F}$ but without streptozotocin. Although D-4F treatment did not alter glucose levels, it significantly increased HO-1 activity in the heart and aorta of the diabetic rats and reduced endothelial sloughing as evidenced by increased $\mathrm{CD} 31^{+}$staining of the endothelium compared to controls. In addition, diabetes caused a significant decrease in aortic thrombomodulin expression that was restored to the levels of the control rats with D-4F treatment.

More recently, Morgantini et al. (2010) studied the effects of D-4F in preventing atherosclerosis development in apo $\mathrm{E}^{-/-}$diabetic mice [82]. Compared to non-diabetic apoE $\mathrm{E}^{-/-}$mice, the diabetic apoE $\mathrm{E}^{-/-}$mice developed roughly $300 \%$ larger lesions, marked dyslipidemia, elevated glucose levels, and reduced plasma insulin levels. Atherosclerotic lesions were significantly reduced in the $\mathrm{D}-4 \mathrm{~F}$-treated diabetic apoE $\mathrm{E}^{-1-}$ mice and the existing lesions had significantly reduced macrophage content relative to non-treated mice. Oxidized lipid concentrations in the liver tissue of diabetic apoE $\mathrm{E}^{-/-}$mice compared with non-diabetic apoE $^{-/-}$mice were significantly reduced by D-4F treatment (Figure 4).

The class of drugs known as apoA-1 expression stimulators can potentially be useful in diabetic patients given that apoA-1 levels are reduced during an acute inflammatory response [83-85]. However, the primary apoA-1 expression stimulator RVX-208 has not been tested yet in human or animal models of diabetes. A phase 1 clinical trial of RVX-208 increased endogenous apoA-1 production and improved HDL-mediated cholesterol efflux [86]. However, results from the phase II clinical trial involving patients with stable coronary artery disease were disappointing, with only a modest $5.6 \%$ increase in apoA-I at the highest dose of RVX-208 [87]. A potentially encouraging sign was a robust $21 \%$ increase in the fraction of large HDL particles, suggesting an improvement in reverse cholesterol transport secondary to greater maturation to the more lipid-rich HDL [88].

\section{Drug therapies that primarily alter the quantity of HDL}

The dilemma of whether raising HDL-C without necessarily improving function can effectively reduce cardiovascular morbidity is best exemplified by the CETP inhibitors. This drug class raises HDL-C by preventing the exchange between HDL-transported cholesterol ester and VLDL-transported triglyceride. A post hoc analysis of the diabetic patient subgroup in a phase III clinical trial of the CETP inhibitor torcetrapib showed a reduction in fasting serum insulin level, plasma glucose, and hemoglobin $\mathrm{A} 1 \mathrm{C}$, but the changes did not correlate with the magnitude in increase of HDL-C levels [89]. Furthermore, the clinical trial was terminated after excess cardiovascular-related morbidity and mortality in the torcetrapib-treated arm, despite increasing HDL-C by

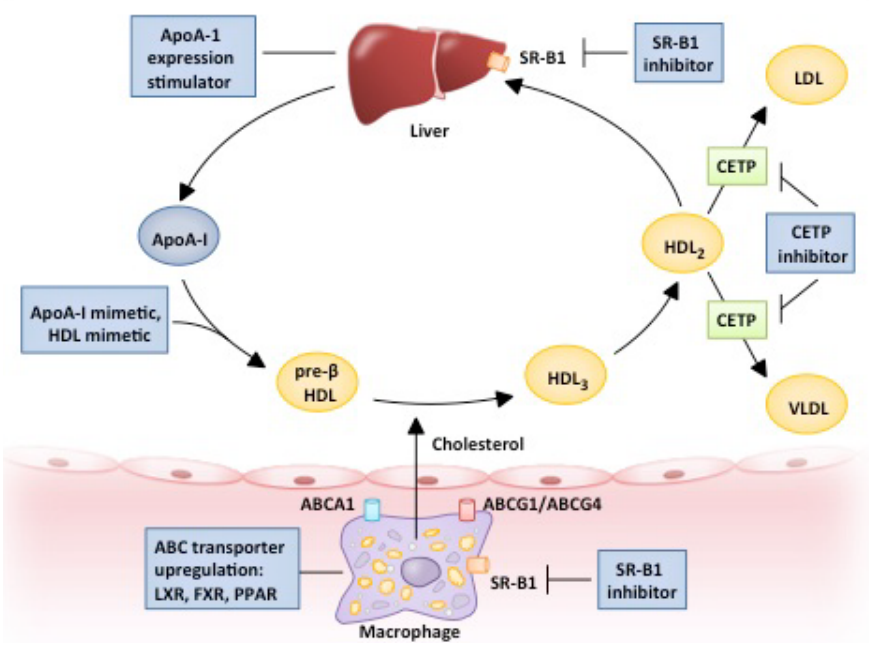

Figure 3: Metabolic pathway of high-density lipoprotein and sites of therapeutic intervention. The formation of nascent high-density lipoprotein molecules begins with apolipoprotein A-I (apoA-I) synthesis in the liver. ApoA-I expression stimulators increase apoA-I synthesis while apoA-I mimetic peptides provide a synthetic surrogate. These apoA-1 molecules and infusible HDL mimetics can then receive cholesterol and phospholipids from macrophages via ATP-binding membrane cassette (ABC) transporter-mediated efflux. The liver $X$ receptor (LXR) agonists, farnesoid $X$ receptor ( $F X R)$ agonists, and peroxisome proliferator-activated receptor (PPAR) agonists can upregulate this lipid efflux process by increasing expression of ABC transporters. Inhibition of cholesteryl ester transfer from the resulting HDL3 (smaller, more dense particles) and HDL2 (larger, less dense particles) via cholesteryl ester transfer protein (CETP) can be blocked by CETP inhibitors. Inhibition of HDL cholesterol uptake by the liver and macrophages via scavenger receptor $\mathrm{BI}$ (SR-BI) inhibitors can also lead to elevated HDL cholesterol levels. Abbreviations: ABCA1, ATP binding membrane cassette transporter A1; ABCG1, ATP binding membrane cassette transporter G1; ABCG4, ATP binding membrane cassette transporter G4; ApoA-I, apolipoprotein A-I; CETP, cholesteryl ester transfer protein; FXR, farnesoid $X$ receptor; HDL, high-density lipoprotein; LXR, liver $X$ receptor; PPAR, peroxisome proliferator-activated receptor; SR-B1, scavenger receptor B1. 


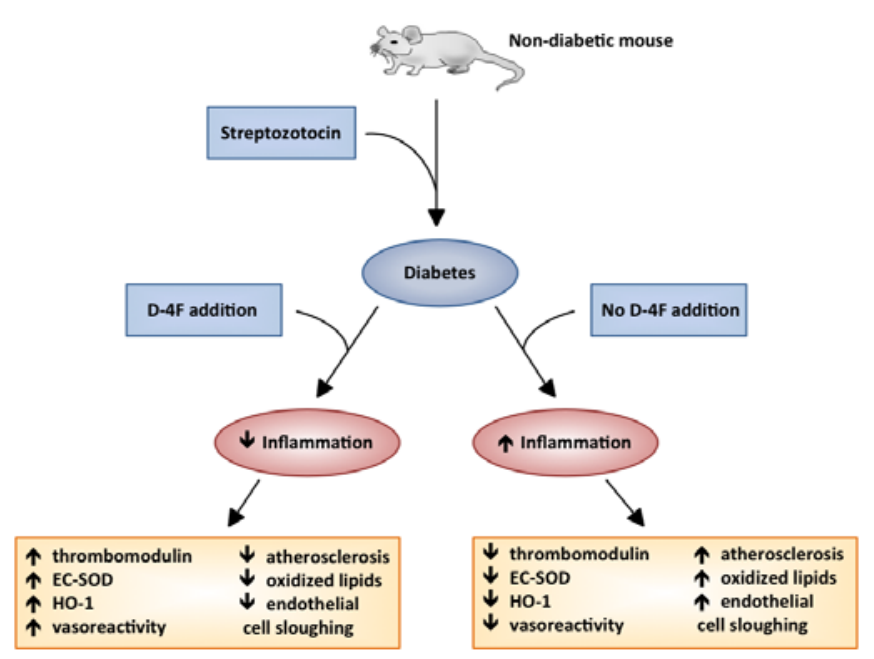

Figure 4: Effects of D-4F treatment in streptozotocin-induced diabetic mice. The induction of diabetes in mice results in hyperglycemia-mediated generation of reactive oxygen species and advanced glycosylation end products. These changes create a systemic inflammatory state that promotes endothelia damage and atheroma formation. Many of these deleterious effects were either diminished or reversed following treatment with apolipoprotein mimetic peptide D-4F. Treatment with D-4F has a vascular protective effect as evidenced by decreased endothelial sloughing and increased thrombomodulin formation, a marker of endothelial cell function. The increase in heme oxygenase 1 (HO-1) and extracellular superoxide dismutase (EC-SOD) helps prevent uncoupling of endothelial nitric oxide synthase and reactive oxygen species formation leading to improved vasoreactivity and vascular repair. D-4F mediated prevention of atherosclerosis development is associated with a reduction in lipid and macrophage content of the atherosclerotic lesions. Abbreviations: EC SOD, extracellular superoxide dismutase; HO-1, heme oxygenase 1.

$72 \%$ and reducing LDL-C by $25 \%$ [90]. It is not entirely clear whether the excess morbidity and mortality were secondary to off-target adverse effects or the creation of dysfunctional HDL [91-93]. The two other CETP inhibitors, dalcetrapib and anacetrapib, are currently undergoing phase III clinical testing and have thus far improved the lipid profile of the study participants without major adverse effects [94-96]

A number of therapies have targeted nuclear metabolic receptors that help regulate glucose and cholesterol homeostasis, including the peroxisome proliferator-activated receptor (PPAR), liver $\mathrm{X}$ receptor(LXR), and farnesoid X receptor (FXR) [97-100]. The antiatherosclerotic activity of these receptors is due in part to their ability to promote cholesterol efflux via the ATP-binding membrane cassette $(\mathrm{ABC})$ transporters $\mathrm{ABCA}-1$ and $\mathrm{ABCG}-1$, which are present on macrophages [101-103]. Cholesterol accumulation in macrophage "foam cells" plays an important role in atherogenesis and studies have shown that chronic hyperglycemia can reduce ABCA-1 and ABCG-1 expression $[104,105]$.

Although there have been no large clinical trials completed showing that nuclear metabolic receptor agonists improve cardiovascular outcomes in diabetic individuals, a number of smaller studies show some potential therapeutic benefit. In phase II clinical trials with the $\mathrm{PPAR} \alpha / \delta$ agonist GFT505, pre-diabetic patients treated with GFT505 had increased insulin sensitivity and increased HDL-C with reduction in plasma glucose, LDL-C, and triglyceride levels; study subjects also had increased levels of apoA-I and reduction of proatherogenic apolipoproteins ApoB and ApoCIII [106]. Treatment with the PPAR $\alpha / \gamma$ agonist aleglitazar in a phase II clinical trial with type 2 diabetic subjects showed dose-dependent improvements in $\mathrm{HbA}_{1 \mathrm{c}}$ concentrations and fasting plasma glucose compared with placebo, and significant dose-dependent changes in all lipid parameters, including an increase in HDL-C levels of up to $28 \%$ [107].

LXR agonists can affect glucose homeostasis by stimulating insulin production, suppressing gluconeogenesis, activating expression of hepatic glucokinase, and increasing GLUT4 expression in adipocytes [108-112]. Administration of LXR agonists has been shown to markedly reduce atherosclerotic lesion formation in multiple murine models of atherosclerosis [113]. Activation of LXR may reduce atherogenesis not only through reverse cholesterol transport, but also by suppressing inflammatory signaling in macrophages to help blunt the associated inflammatory response in atherosclerosis $[113,114]$. However, enthusiasm for LXR agonists has been tempered by evidence that some non-selective LXR agonistsinduce hepatic steatosis and hypertriglyceridemia [115,116]. Other adverse lipogenic effects include chronic stimulation of lipogenesis in $\beta$-cells that may induce apoptosis as well as reduced expression of hepatic and adipose glycolytic enzymes [117].

FXR expression is diminished in livers of streptozotocin-induced diabetic mice and its deficiency is associated with impaired glucose tolerance and insulin resistance $[118,119]$. Treatment with FXR agonists in diabetic mice results in enhanced insulin sensitivity, increased hepatic glycogen synthesis, and reduced hepatic gluconeogenesis $[119,120]$. Mauldin et al. (2008) showed that LXR agonist treatment of monocyte-derived macrophages from diabetic subjects resulted in dramatically reduced foam cell formation [104]. While there has been no investigation of atherosclerosis progression in a murine model of diabetes, administering the FXR agonist INT-747 in apolipoprotein E-deficient mice reduced the extent of atherosclerotic plaques in a dose-dependent manner [121].

The scavenger receptor BI (SR-BI) inhibitors are a relatively newer drug class that has yet to be studied in a clinical model of diabetes. SR-BI is a major regulatory factor inHDL catabolism that binds HDL and mediates the selective uptake of HDL cholesteryl ester in the liver and steroidogenic tissues for eventual excretion [122]. Diabetic mice peritoneal macrophages show SR-BI overexpression that results in net HDL-mediated cholesterol influx and greater total cellular cholesterol, which may promote foam cell formation and atherogenesis [123].

\section{Conclusion}

The treatment and management of diabetic dyslipidemia first and foremost requires lifestyle changes to help reduce cardiovascular risk, including increased physical activity, improved diet, and weight reduction. However, given the difficulty of managing the disease with lifestyle modifications alone, medications are needed to achieve therapeutic targets. The complexity of diabetic dyslipidemia is such that even optimal combinations of current first- and second-line lipidlowering agents still leave residual cardiovascular risk. There is now a greater focus on developing treatments that target HDL as a means of reducing atherogenesis. However, the oxidative environment in a hyperglycemic state modifies the composition of HDL such that it has diminished ability to promote cholesterol efflux and acts as a proinflammatory agent.

Given the evidence that HDL becomes pro-inflammatory in a chronic disease state like diabetes, simply raising HDL-C levels may not be the ideal target for measuring success of new therapies targeting HDL. The complexity of HDL metabolism and the various functional roles it plays make the HDL-C level a weak indicator of potential 
Citation: Elboudwarej O, Hojjat H, Safarpoor S, Vazirian S, Ahmadi S (2011) Dysfunctional HDL and Cardiovascular Disease Risk in Individuals with Diabetic Dyslipidemia. J Diabetes Metab S4:001. doi:10.4172/2155-6156.S4-001

therapeutic benefit. Thus, therapies that effectively slow the catabolic rate of HDL, such as the CETP inhibitors and SR-B1 inhibitors, may raise dysfunctional HDL levels in diabetic patients. The more effective approach for reducing cardiovascular risk likely lies with therapies that target the composition and function of HDL. Therapies that promote apoA-1 production or act as surrogate apoA-1 peptides target the fundamental problem with HDL in a chronic hyperglycemic state, which is the loss of its antioxidant and anti-inflammatory properties. In particular, the apolipoprotein mimetic peptides help restore function to the existing pool of HDL molecules in the body and reverse the effects caused by the glycation of HDL.

It must be acknowledged that therapies that do not target improving the function of HDL, such as the nuclear metabolic receptor drug classes, have shown some benefit in early studies. Their value may arise from mitigating the inflammatory component that accelerates atherogenesis, such as improving glycemic control or inhibiting pro-inflammatory genes in macrophages. More importantly, the ability of these receptors to promote reverse cholesterol transport can be viewed as improving one of the functional roles of HDL. Nonetheless, measuring steadystate HDL-C levels as a benchmark for therapeutic success may not accurately assess a kinetic process like reverse cholesterol transport $[124,125]$. The identification of novel biomarkers and tools to measure the function of HDL in preclinical trials may ultimately prove to be a better predictor of success for diabetic individuals in large-scale cardiovascular outcome trials.

\section{Review Criteria}

The articles selected for this Review were obtained from searches of PubMed using the terms "diabetic dyslipidemia", "atherosclerosis", "type 2 diabetes mellitus", "dysfunctional HDL", "oxidized lipoprotein", "cardiovascular disease", "apolipoprotein mimetic peptides", "apolipoprotein expression stimulators", "CETP inhibitors", "PPAR agonists", "Liver X receptor agonists", "HDL mimetics", "Farnesoid X receptor agonists", and "Scavenger receptor BI inhibitors." Selected papers were full-text original articles and reviews published between 1970 and 2011. Abstracts were not included. Reference lists of the identified papers were searched for additional material.

\section{References}

1. Howard B, Best L, Galloway J, Howard W, Jones K, et al. (2006) Coronary heart disease risk equivalence in diabetes depends on concomitant risk factors. Diabetes Care 29: 391-397.

2. Schramm TK, Gislason GH, Kober L, Rasmussen S, Rasmussen JN, et al (2008) Diabetes patients requiring glucose-lowering therapy and nondiabetics with a prior myocardial infarction carry the same cardiovascular risk: a population study of 3.3 million people. Circulation 117: 1945-1954.

3. Ouhoummane N, Abdous B, Louchini R, Rochette L, Poirier P (2010) Trends in postacute myocardial infarction management and mortality in patients with diabetes. A population-based study from 1995 to 2001. Can J Cardiol 26: 523531

4. Juutilainen A, Lehto S, Rönnemaa T, Pyörälä K, Laakso M (2005) Type 2 diabetes as a "coronary heart disease equivalent": an 18-year prospective population-based study in Finnish subjects. Diabetes Care 28: 2901-2907.

5. Stamler J, Daviglus M, Garside D, Dyer A, Greenland P, et al. (2000) Relationship of baseline serum cholesterol levels in 3 large cohorts of younger men to long-term coronary, cardiovascular, and all-cause mortality and to longevity. JAMA 284: 311-318.

6. Almdal T, Scharling $\mathrm{H}$, Jensen J, Vestergaard $\mathrm{H}$ (2004)The independent effect of type 2 diabetes mellitus on ischemic heart disease, stroke, and death: a population-based study of 13,000 men and women with 20 years of follow-up. Arch Intern Med 164: 1422-1426.

7. Grundy S, Cleeman J, Merz C, Brewer H Jr, Clark L, et al. (2004) Implications of recent clinical trials for the National Cholesterol Education Program Adult Treatment Panel III guidelines. Circulation 110: 227-239.

8. Expert panel on Detection, Evaluation, and Treatment of High Blood Cholesterol in Adults (2001) Executive Summary of the Third Report of the National Cholesterol Education Program (NCEP) Expert Panel on Detection, Evaluation and Treatment of High Blood Cholesterol in Adults (Adult Treatment Panel III) JAMA 285: 2486-2497.

9. Stamler J, Vaccaro O, Neaton J, Wentworth D (1993) Diabetes, other risk factors, and 12-yr cardiovascular mortality for men screened in the Multiple Risk Factor Intervention Trial. Diabetes Care 16: 434-444.

10. Krauss R (2004) Lipids and lipoproteins in patients with type 2 diabetes. Diabetes Care 27: 1496-1504.

11. (1997) U.K. Prospective Diabetes Study 27. Plasma lipids and lipoproteins a diagnosis of NIDDM by age and sex. Diabetes Care 20: 1683-1687.

12. Garvey W, Kwon S, Zheng D, Shaughnessy S, Wallace P, et al. (2003) Effects of insulin resistance and type 2 diabetes on lipoprotein subclass particle size and concentration determined by nuclear magnetic resonance. Diabetes 52 453-462.

13. Boden G, Laakso M (2004) Lipids and glucose in type 2 diabetes: what is the cause and effect? Diabetes Care 27: 2253-2259.

14. Ginsberg HN, Zhang YL, Hernandez-Ono A (2005) Regulation of plasma triglycerides in insulin resistance and diabetes. Arch Med Res 36: 232-240.

15. Adiels M, Olofsson S, Taskinen M, Boren J (2006) Diabetic dyslipidaemia. Curr Opin Lipidol 17: 238-246.

16. Laakso M (2009) Lipid disorders in type 2 diabetes. Endocrinol Nutr 56 : 43-45

17. Del Pilar Solano M, Goldberg R (2005) Management of diabetic dyslipidemia Endocrinol Metab Clin North Am 34: 1-25.

18. Chahil T, Ginsberg H (2006) Diabetic dyslipidemia. Endocrinol Metab Clin North Am 35: 491-510.

19. Frayn K (2001) Adipose tissue and the insulin resistance syndrome. Proc Nutr Soc 60: 375-380.

20. Mooradian A, Haas M, Wehmeier K, Wong N (2008)Obesity-related changes in high density lipoprotein metabolism. Obesity 16: 1152-1160.

21. Rader D (2006) Molecular regulation of HDL metabolism and function: implications for novel therapies. J Clin Invest 116: 3090-3100.

22. Dunn FL (2010) Management of dyslipidemia in people with type 2 diabetes mellitus. Rev Endocr Metab Disord 11: 41-51.

23. Dullaart R, De Vries R, Scheek L, Borrgreve S, Van Gent T,et al. (2004) Type 2 diabetes mellitus is associated with differential effects on plasmacholestery ester transfer protein and phospholipid transfer protein activities and concentrations. Scand J Clin Lab Invest 64: 205-215.

24. de Vries R, Borggreve S, Dullaart R (2003) Role of lipases, lecithin:cholestero acyltransferase and cholesteryl ester transfer protein in abnormal high density lipoprotein metabolism in insulin resistance and type 2 diabetes mellitus. Clin Lab 49: 601-613.

25. de Vries R, Perton F, Dallinga-Thie G, van Roon A, Wolffenbuttel B, et al. (2005) Plasma cholesterol ester transfer is a determinant of intima-media thickness in type 2 diabetic and nondiabetic subjects: role of CETP and triglycerides Diabetes 54: 3554-3559.

26. Vergès B, Petit JM, Duvillard L, Dautin G, Florentin E, et al. (2006) Adiponectin is an important determinant of ApoA-I catabolism. Arterioscler Thromb Vasc Biol 26: 1364-1369.

27. de Vries R, Dallinga-Thie G, Smit A,Wolffenbuttel B, van Tol A, et al. (2006) Elevated plasma phospholipid transfer protein activity is a determinant of carotid intima-media thickness in type 2 diabetes mellitus. Diabetologia 49 : 398-404.

28. Zhang Y, Zanotti I, Reilly MP, Glick JM, Rothblat GH, et al. (2003) Overexpression of apolipoprotein A-I promotes reverse transport of cholesterol from macrophages to feces in vivo. Circulation 108: 661-663.

29. Moore R, Navab M, Millar J, Zimetti F, Hama S, et al. (2005) Increased atherosclerosis in mice lacking apolipoprotein A-I attributable to both impaired reverse cholesterol transport and increased inflammation. Circ Res 97: 763 771.

30. Navab M, Berliner J, Subbanagounder G, Hama S, Lusis A, et al. (2001) HDL and the inflammatory response induced by LDL-derived oxidized phospholipids. Arterioscl Thromb Vasc Biol 21: 481-488. 
Citation: Elboudwarej O, Hojjat H, Safarpoor S, Vazirian S, Ahmadi S (2011) Dysfunctional HDL and Cardiovascular Disease Risk in Individuals with Diabetic Dyslipidemia. J Diabetes Metab S4:001. doi:10.4172/2155-6156.S4-001

31. Navab M, Imes S, Hama S, Hough G, Ross L, et al. (1991) Monocyte transmigration induced by modification of low density lipoprotein in cocultures of human aortic wall cells is due to induction of monocyte chemotactic protein 1 synthesis and is abolished by high density lipoprotein. J Clin Invest 88: 20392046.

32. Nofer J, van der Giet M, Tolle M, Wolinska I, von Wnuck Lipinski K, et al. (2004) $\mathrm{HDL}$ induces NO-dependent vasorelaxation via the lysophospholipid recepto S1P3. J Clin Inves 113: 569-581.

33. Xia P, Vadas M, Rye K, Barter P, Gamble J (1999) High density lipoproteins $(\mathrm{HDL})$ interrupt the sphingosine kinase signaling pathway. A possible mechanism for protection against atherosclerosis by HDL. J Biol Chem 274 : 33143-33147.

34. Nofer J, Levkau B, Wolinska I, Junker R, Fobker M, et al. (2001) Suppression of endothelial cell apoptosis by high density lipoproteins (HDL) and HDLassociated lysosphingolipids. J Biol Chem 276: 34480-34485

35. Nofer JR, Brodde MF, Kehrel BE (2010) High-density lipoproteins, platelets and the pathogenesis of atherosclerosis. Clin Exp Pharmacol Physiol 37: 726-735.

36. Navab M, Ananthramaiah G, Reddy S, Van Lenten B, Ansell B, et al. (2005) The double jeopardy of HDL. Ann Med 37: 173-178.

37. Gordon T, Castelli W, Hjortland M, Kannel W, Dawber T (1977) High density lipoprotein as a protective factor against coronary heart disease. Am J Med 62: 707-714.

38. Navab M, Ananthramaiah G, Reddy S, Van Lenten B, Ansell B, et al. (2004)The oxidation hypothesis of atherogenesis: the role of oxidized phospholipids and HDL. J Lipid Res 45: 993-1007.

39. Van Lenten B, Hama S, de Beer F, Stafforini D, Mclntyre T, et al. (1995) Anti-inflammatory HDL becomes pro-inflammatory during the acute phase response: loss of protective effect of HDL against LDL oxidation in aortic wall cell cultures. J Clin Invest 96: 2758-2767.

40. Bielicki J, Forte T (1999) Evidence that lipid hydroperoxides inhibit plasma lecithin:cholesterol acyltransferase activity. J Lipid Res 40: 948-954.

41. Forte TM, Subbanagounder G, Berliner JA, Blanche PJ, Clermont AO, et al (2002) Altered activities of antiatherogenic enzymes, LCAT, paraoxonase, and platelet activating factor acetylhydrolase in atherosclerosis susceptible mice. $J$ Lipid Res 43: 477-485.

42. Navab M, Hama S, Hough G, Subbanagounder G, Reddy S, et al. (2001) A cellfree assay for detecting HDL that is dysfunctional in preventing the formation of or inactivating oxidized phospholipids. J Lipid Res 42: 1308-1317.

43. Hedrick C, Thorpe S, Fu M, Harper C, Yoo J, et al. (2000) Glycation impairs high-density lipoprotein function. Diabetologia 43: 312-320.

44. Mackness B, Hine D, Liu Y, Mastorikou M, Mackness M (2004) Paraoxonase 1 inhibits oxidised LDL-induced MCP-1 production by endothelial cells. Biochem Biophys Res Commun 318: 680-683.

45. Sampson M, Braschi S, Willis G, Astley S (2005) Paraoxonase-1 (PON1) genotype and activity and in vivo oxidised, plasma low-density lipoprotein in Type II diabetes. Clin Sci 109: 189-197.

46. Tsuzura S, Ikeda Y, Suehiro T, Ota K, Osaki F, et al. (2004) Correlation of plasma oxidized low-density lipoprotein levels to vascular complications and human serum paraoxonase in patients with Type 2 diabetes. Metabolism 53 297-302.

47. Morgantini C, Natali A, Boldrini B, Imaizumi S, Navab M, et al. (2011) Antiinflammatory and antioxidant properties of HDLs are impaired in type 2 diabetes. Diabetes 60: 2617-2623.

48. McMahon M, Grossman J, Skaggs B, Fitzgerald J, Sahakian L, et al. (2009) Dysfunctional proinflammatory high-density lipoproteins confer increased risk of atherosclerosis in women with systemic lupus erythematosus. Arthritis Rheum 60: 2428-2437.

49. Chait A, Han CY, Oram JF, Heinecke JW (2005) Thematic review series: The immune system and atherogenesis. Lipoprotein-associated inflammatory proteins: markers or mediators of cardiovascular disease? J Lipid Res 46: 389 403

50. Asleh R, Miller-Lotan R, Aviram M, Hayek T, Yulish M, et al. (2006) Haptoglobin genotype is a regulator of reverse cholesterol transport in diabetes in vitro and in vivo. Circ Res 99: 1419-1425.

51. Perségol L, Foissac M, Lagrost L, Athias A, Gambert P, et al. (2007) HDL particles from type 1 diabetic patients are unable to reverse the inhibitory effect of oxidised LDL on endothelium-dependent vasorelaxation. Diabetologia 50 2384-2387.

52. Perségol L, Vergès B, Foissac M, Gambert P, Duvillard L (2006) Inability of HDL from type 2 diabetic patients to counteract the inhibitory effect of oxidized LDL on endothelium-dependent vasorelaxation. Diabetologia 49: 1380-1386.

53. Gordon D, Probstfield J, Garrison R, Neaton J, Castelli W, et al. (1989) Highdensity lipoprotein cholesterol and cardiovascular disease. Four prospective American studies. Circulation 79: 8-15.

54. Cooney M, Dudina A, De Bacquer D, Wilhelmsen L, Sans S, et al. (2009) HDL cholesterol protects against cardiovascular disease in both genders, at all ages and at all levels of risk. Atherosclerosis 206: 611-616.

55. Roberts CK, Ng C, Hama S, Eliseo AJ, Barnard RJ (2006) Effect of a short-term diet and exercise intervention on inflammatory/anti-inflammatory properties of $\mathrm{HDL}$ in overweight/obese men with cardiovascular risk factors. J Appl Physio 101: 1727-1732.

56. Briel M, Ferreira-Gonzalez I, You J, Karanicolas P, Akl E, et al. (2009) Association between change in high density lipoprotein cholesterol and cardiovascular disease morbidity and mortality: systematic review and metaregression analysis. BMJ 338: 92.

57. Alexander ET, Tanaka M, Kono M, Saito H, Rader D, et al. (2009) Structura and functional consequences of the Milano mutation (R173C) in human apolipoprotein A-I. J Lipid Res. 50: 1409-1419.

58. van der Steeg W, Holme I, Boekholdt M, Larsen M, Lindahl C, et al. (2008) High-density lipoprotein cholesterol, high-density lipoprotein particle size, and apolipoprotein A-I: significance for cardiovascular risk. J Am Coll Cardiol 51 634-642.

59. Dunn F (2010) Management of dyslipidemia in people with type 2 diabetes mellitus. Rev Endocr Metab Disord 11:41-51.

60. Garvey W, Kwon S, Zheng D, Shaughnessy S, Wallace P, et al. (2003) Effects of insulin resistance and type 2 diabetes on lipoprotein subclass particle size and concentration determined by nuclear magnetic resonance. Diabetes 52 : 453-462.

61. Ginsberg H, Zhang Y, Hernandez-Ono A (2005) Regulation of plasma triglycerides in insulin resistance and diabetes. Arch Med Res 36: 232-240.

62. Emanuele N, Azad N, Abraira C, Henderson W, Colwell J, et al. (1998) Effect of intensive glycemic control on fibrinogen, lipids, and lipoproteins: Veterans affairs cooperative study in type II diabetes mellitus. Arch Intern Med 158: 2485-2490.

63. Krauss R (2004) Lipids and lipoproteins in patients with type 2 diabetes. Diabetes Care 27:1496-1504

64. Colhoun H, Betteridge D, Durrington P, Hitman G, Neil H, et al. (2004) Primary prevention of cardiovascular disease with atorvastatin in type 2 diabetes in the Collaborative Atorvastatin Diabetes Study (CARDS): multicentre randomised placebo-controlled trial. Lancet 364: 685-696.

65. Nicholls S, Tuzcu E, Kalidindi S, Wolski K, Moon K, et al. (2008) Effect of diabetes on progression of coronary atherosclerosis and arterial remodeling: a pooled analysis of 5 intravascular ultrasound trials. J Am Coll Cardiol 52: 255 262

66. Libby P (2005) The forgotten majority: unfinished business in cardiovascular risk reduction. J Am Coll Cardiol 46: 1225-1228.

67. Barter P, Gotto AM, LaRosa JC, Maroni J, Szarek M, et al. (2007) HDL cholesterol, very low levels of LDL cholesterol, and cardiovascular events. N Engl J Med 357: 1301-1310.

68. Drew B, Duffy S, Formosa M, Natoli A, Henstridge D, et al. (2009) High-density lipoprotein modulates glucose metabolism in patients with type 2 diabete mellitus. Circulation 119: 2103-2111.

69. Calkin AC, Drew BG, Ono A, Duffy SJ, Gordon MV, et al. (2009) Reconstituted High-Density Lipoprotein Attenuates Platelet Function in Individuals With Type 2 Diabetes Mellitus by Promoting Cholesterol Efflux. Circulation 120: 2095 2104

70. Abderrahmani A, Niederhauser G, Favre D, Abdelli S, Ferdaoussi M, et al. (2007) Human high-density lipoprotein particles prevent activation of the Jnk pathway induced by human oxidised low-density lipoprotein particles in pancreatic beta cells. Diabetologia 50: 1304-1314. 
Citation: Elboudwarej O, Hojjat H, Safarpoor S, Vazirian S, Ahmadi S (2011) Dysfunctional HDL and Cardiovascular Disease Risk in Individuals with Diabetic Dyslipidemia. J Diabetes Metab S4:001. doi:10.4172/2155-6156.S4-001

71. van Oostrom $O$, Nieuwdorp $M$, Westerweel PE, Hoefer IE, Basser $R$, et al. (2007) Reconstituted HDL increases circulating endothelial progenitor cells in patients with type 2 diabetes. Arterioscler Thromb Vasc Biol 27: 1864-1865.

72. Nieuwdorp M, Vergeer M, Bisoendial RJ, op 't Roodt J, Levels H, et al.(2008) Reconstituted HDL infusion restores endothelial function in patients with type 2 diabetes mellitus. Diabetologia 51: 1081-1084

73. Drew B, Duffy S, Formosa M, Natoli A, Henstridge D, et al. (2009) High-density lipoprotein modulates glucose metabolism in patients with type 2 diabetes. Circulation 119: 2103-2111.

74. Anantharamaiah G, Jones L, Brouillette C, Schmidt C, Chung B, et al.(1985) Studies of synthetic peptide analogs of amphipathic helix I: structure of peptide/ DMPC complexes. J Biol Chem 260: 10248-10255.

75. Venkatachalapathi Y, Phillips M, Epand RM, Epand RF, Tytler E, et al. (1993) Effect of end group blockage on the properties of a class $A$ amphipathic helical peptide. Proteins 15: 349-359.

76. Yancey P, Bielicki J, Lund-Katz S, Pulgunachari M, Anantharamaiah G, et al. (1995) Efflux of cellular cholesterol and phospholipid to lipid-free apolipoproteins and class A amphipathic peptides. Biochemistry 34: 7955-7965.

77. Tardif J, Heinonen T, Noble S (2009) High-density lipoprotein/apolipoprotein A-I infusion therapy. Curr Atheroscler Rep 11: 58-63.

78. Navab M, Anantharamaiah G, Reddy S, Hama S, Hough G, et al. (2004) Oral D-4F causes formation of pre- $\beta$ high-density lipoprotein and improves high-density lipoprotein-mediated cholesterol efflux and reverse cholesterol transport from macrophages in apolipoprotein E-null mice. Circulation 109: 3215-3220.

79. Navab M, Anantharamaiah G, Reddy S, Hama S, Hough G, et al. (2005) Apolipoprotein A-I mimetic peptides. Arterioscler Thromb Vasc Biol 25:13251331.

80. Kruger A, Peterson S, Turkseven S, Kaminski P, Zhang F, et al. (2005) D-4F induces heme oxygenase-1 and extracellular superoxide dismutase, decreases endothelial cell sloughing, and improves vascular reactivity in rat model of diabetes. Circulation 111: 3126-3134.

81. Peterson S, Husney D, Kruger A, Olszanecki R, Ricci F, et al. (2007) Long-term treatment with the apolipoprotein A1 mimetic peptide increases antioxidants and vascular repair in type I diabetic rats. J Pharmacol Exp Ther 322: 514-520.

82. Morgantini C, Imaizumi S, Grijalva V, Navab M, Fogelman A, et al. (2010) Apolipoprotein A-I Mimetic Peptides Prevent Atherosclerosis Development and Reduce Plaque Inflammation in a Murine Model of Diabetes. Diabetes 59: 3223-3228.

83. Cabana V, Siegel J, Sabesin S(1989) Effects of the acute phase response on the concentration and density distribution of plasma lipids and apolipoproteins. J Lipid Res 30: 39-49.

84. Pruzanski W, Stefanski E, de Beer F, de Beer M, Ravandi A, et al. (2000) Comparative analysis of lipid composition of normal and acute-phase high density lipoproteins. J Lipid Res 41: 1035-1047.

85. Tietge U, Maugeais J, Lund-Katz S, Grass D, de Beer F, et al. (2002) Human secretory phospholipase A2 mediates decreased plasma levels of HDL cholesterol and apoA-I in response to inflammation in human apoA-I transgenic mice. Arterioscler Thromb Vasc Biol 22: 1213-1218.

86. Bailey D, Jahagirdar R, Gordon A, Hafiane A, Campbell S, et al. (2010) RVX208: a small molecule that increases apolipoprotein A-I and high-density lipoprotein cholesterol in vitro and in vivo. J Am Coll Cardiol 55: 2580-2589.

87. Nicholls S, Gordon A, Johansson J, Wolski K, Ballantyne C, et al. (2011) Efficacy and safety of a novel oral inducer of apolipoprotein a-l synthesis in statin-treated patients with stable coronary artery disease a randomized controlled trial. J Am Coll Cardiol57: 1111-1119.

88. Davidson MH (2011) Apolipoprotein A-1 therapy promise, challenges, and disappointment. J Am Coll Cardio I57: 1120-1121.

89. Barter P, Rye K, Tardif J, Waters D, Boekholdt M, et al. (2011) Effect of Torcetrapib on Glucose, Insulin, and Hemoglobin $A_{1}$ in Subjects in the Investigation of Lipid Level Management to Understand its Impact in Atherosclerotic Events (ILLUMINATE) Trial. Circulation 124: 555-562.

90. Barter P, Caulfield M, Eriksson M, Grundy S, Kastelein J, et al. (2007) Effects of torcetrapib in patients at high risk for coronary events. N Engl J Med 357 $2109-2122$.
91. Hu X, Dietz J, Xia C, Knight D, Loging W, et al. (2009) Torcetrapib induces aldosterone and cortisol production by an intracellular calcium-mediated mechanism independently of cholesteryl ester transfer protein inhibition. Endocrinology 150: 2211-2219.

92. Clerc R, Stauffer A, Weibel F, Hainaut E, Perez A, et al. (2010) Mechanisms underlying off-target effects of the cholesteryl ester transfer protein inhibitor torcetrapib involve L-type calcium channels. J Hypertens 28: 1676-1686.

93. Forrest M, Bloomfield D, Briscoe R, Brown P, Cumiskey A, et al. (2008) Torcetrapib-induced blood pressure elevation is independent of CETP inhibition and is accompanied by increased circulating levels of aldosterone. $\mathrm{Br}$ J Pharmacol 154: 1465-1473

94. Davidson M (2010) Update on CETP inhibition. J Clin Lipidol 4: 394-398.

95. Bloomfield D, Carlson G, Sapre A, Tribble D, McKenney J, et al. (2009) Efficacy and safety of the cholesteryl ester transfer protein inhibitor anacetrapib as monotherapy and coadministered with atorvastatin in dyslipidemic patients. Am Heart J 157: 352-360.

96. Stein E, Stroes E, Steiner G, Buckley B, Capponi A, et al. (2009) Safety and tolerability of dalcetrapib. Am J Cardiol 104: 82-91

97. Lefebvre P, Chinetti G, Fruchart J, Staels B (2006) Sorting out the roles of PPARa in energy metabolism and vascular homeostasis. J Clin Invest 116 571-580.

98. Mohan R, Heyman R (2003) Orphan nuclear receptor modulators. Curr Top Med Chem 3: 1637-1647.

99. Zhang $Y$, Kast-Woelbern H, Edwards P (2003) Natural structural variants of the nuclear receptor farnesoid $X$ receptor affect transcriptional activation. J Bio Chem 278: 101-110.

100. Lee F, Lee H, Hubbert M, Edwards P, Zhang Y (2006) FXR, a multipurpose nuclear receptor. Trends Biochem Sci 31: 572-580.

101. Beyea M, Heslop C, Sawyez C, Edwards J, Markle J, et al. (2007) Selective up-regulation of LXR-regulated genes ABCA1, ABCG1, and APOE in macrophages through increased endogenous synthesis of 24(S),25epoxycholesterol. J Biol Chem 282: 5207-5216.

102. Li A, Binder C, Gutierrez A, Brown K, Plotkins C, et al. (2004) Differentia inhibition of macrophage foam-cell formation and atherosclerosis in mice by PPARa, $\beta / \delta$, and $\mathrm{y}$. J Clin Invest114: 1564-1576.

103. Larrede S, Quinn C, Jessup W, Frisdal E, Olivier M, et al. (2009) Stimulation of Cholesterol Efflux by LXR Agonists in Cholesterol-Loaded Human Macrophages Is ABCA1-Dependent but ABCG1-Independent. Arterioscler Thromb Vasc Biol 29: 1930-1936.

104. Mauldin J, Nagelin M, Wojcik A, Srinivasan S, Skaflen M, et al. (2008) Reduced Expression of ATP-Binding Cassette Transporter G1 Increase Cholesterol Accumulation in Macrophages of Patients With Type 2 Diabetes Mellitus. Circulation 117: 2785-2792.

105. Iborra T, Machado-Lima A, Castilho G, Nunes V, Abdalla D, et al. (2011) Advanced Glycation in macrophages induces intracellular accumulation of 7-ketocholesterol and total sterols by decreasing the expression of ABCA-1 and ABCG-1. Lipids Health Dis 10: 172

106. Hanf R, Bruckert E, Cariou B, Staels B (2010) GFT505 Improves Glucose and Lipid Homeostasis in Patients with Impaired Fasting Glucose and Impaired Glucose Tolerance. American Diabetes Association, 70th Scientific Session, 2010

107. Henry R, Lincoff A, Mudaliar S, Rabbia M, Chognot C, et al. (2009) Effect of the dual peroxisome proliferator-activated receptor-alpha/gamma agonis aleglitazar on risk of cardiovascular disease in patients with type 2 diabetes (SYNCHRONY): a phase II, randomised, dose-ranging study. Lancet 374 126-135

108. Laffitte B, Chao L, Li J, Walczak R, Hummasti S, et al. (2003) Activation of liver $X$ receptor improves glucose tolerance through coordinate regulation of glucose metabolism in liver and adipose tissue. Proc Natl Acad Sci 100: 54195424

109. Stulnig T, Steffensen K, Gao H, Reimers M, Dahlman-Wright K, et al. (2002) Novel roles of liver $X$ receptors exposed by gene expression profiling in liver and adipose tissue. Mol Pharmacol 62: 1299-1305.

110. Grefhorst A, van Dijk T, Hammer A, van der Sluijs F, Havinga R, et al. (2005) 
Citation: Elboudwarej O, Hojjat H, Safarpoor S, Vazirian S, Ahmadi S (2011) Dysfunctional HDL and Cardiovascular Disease Risk in Individuals with Diabetic Dyslipidemia. J Diabetes Metab S4:001. doi:10.4172/2155-6156.S4-001

Differential effects of pharmacological liver $X$ receptor activation on hepatic and peripheral insulin sensitivity in lean and ob/ob mice. Am J Physiol Endocrinol Metab 289: E829-E838.

111. Cao G, Liang Y, Broderick C, Oldham B, Beyer T, et al. (2003) Antidiabetic action of a liver $\mathrm{x}$ receptor agonist mediated by inhibition of hepatic gluconeogenesis. J Biol Chem 278: 1131-1136.

112. Dalen K, Ulven S, Bamberg K, Gustafsson J, Nebb H (2003) Expression of the insulin-responsive glucose transporter GLUT4 in adipocytes is dependent on liver X receptor alpha. J Biol Chem 278: 48283-48291.

113. Joseph S, McKilligin E, Pei L, Watson M, Collins A, et al. (2002) Synthetic LXR ligand inhibits the development of atherosclerosis in mice. Proc Natl Acad Sci U S A 99: 7604-7609.

114. Im SS, Psborne $T$ (2011) Liver X Receptors in Atherosclerosis and Inflammation. Circulation Research 108: 996-1001.

115. Repa J, Liang G, Ou J, Bashmakov Y, Lobaccaro JM, et al. (2000). Regulation of mouse sterol regulatory element-binding protein-1c gene (SREBP-1c) by oxysterol receptors, LXRalpha and LXRbeta. Genes Dev 14: 2819-2830.

116. Schultz J, Tu H, Luk A, Repa J, Medina J, et al. (2000). Role of LXRs in control of lipogenesis. Genes Dev 14: 2831-2838.

117. Choe S, Choi A, Lee J, Kim K, Chung J, et al. (2007) Chronic activation of liver $X$ receptor induces beta-cell apoptosis through hyperactivation of lipogenesis: liver $X$ receptor-mediated lipotoxicity in pancreatic beta-cells. Diabetes 56 : 1534-1543.
118. Duran-Sandoval D, Mautino G, Martin G, Percevault F, Barbier O, et al. (2004) Glucose Regulates the Expression of the Farnesoid $X$ Receptor in Liver. Diabetes 53: 890-898

119. Cariou B, van Harmelen K, Duran-Sandoval D, van Dijk TH, Grefhorst A, et al. (2006) The farnesoid $X$ receptor modulates adiposity and peripheral insulin sensitivity in mice. J Biol Chem 281: 11039-11049.

120.Zhang Y, Lee F, Barrera G, Lee H, Vales C, et al. (2006). Activation of the nuclear receptor FXR improves hyperglycemia and hyperlipidemia in diabetic mice. PNAS 103: 1006-1011.

121. Mencarelli A, Renga B, Distrutti E, Fiorucci S (2009) Antiatherosclerotic effect of farnesoid X receptor. AJP-Heart 296: H272-H281.

122. Acton S, Rigotti A, Landschulz K, Xu S, Hobbs H, et al. (1996) Identification of scavenger receptor SR-BI as a high density lipoprotein receptor. Science 271 518-520.

123. Gantman A, Fuhrman B, Aviram M, Hayek T (2010) High glucose stimulates macrophage SR-BI expression and induces a switch in its activity from cholesterol efflux to cholesterol influx. Biochem Biophys Res Commun 391: 523-528.

124. Lewis G, Rader D (2005) New insights into the regulation of HDL metabolism and reverse cholesterol transport. Circ Res 96: 1221-1232.

125.Duffy D, Rader D (2006) Emerging Therapies Targeting High-Density Lipoprotein Metabolism and Reverse Cholesterol Transport. Circulation 113 1140-1150.
This article was originally published in a special issue, Diabetic Cardiovascular Complications handled by Editor(s). Dr. Zhengyuan Xia, University of Hong Kong, Hong Kong 